\title{
Labour force participation and employment among a sample of Australian patients with a spinal cord injury
}

\author{
G Murphy ${ }^{1}$, D Brown ${ }^{2}, \mathrm{~J}_{\text {Athanasou }}^{3}$ P Foreman $^{1}$ and A Young ${ }^{1}$ \\ ${ }^{1}$ School of Behavioural Health Sciences, La Trobe University, Bundoora, 3083 Australia; ${ }^{2}$ Spinal Injuries Unit, Austin \\ Hospital, Heidelberg, 3084 Australia; ${ }^{3}$ School of Adult Vocational Education, University of Technology, Sydney, \\ 2007, Australia
}

\begin{abstract}
This study examined the employment achievements of 219 spinal cord injured people and attempted to identify predictors which, individually and in combination, (a) discriminated between those who were in the labour force or not, and (b) correlated with the amount of time in employment post injury. Results indicated that at the time of the survey $26 \%$ were in fulltime work, $11 \%$ were in part-time work, 4\% were unemployed and 59\% were not actively seeking work. Multivariate analyses identified three variables (impairment type, study since injury, level of pre-injury secondary schooling) which were related to both labour force participation and the amount of work undertaken post-injury. These results are discussed with reference to post-injury services that could be offered to spinal cord injured people who wish to return to work or gain employment.
\end{abstract}

Keywords: spinal cord injury; employment; unemployment; rehabilitation vocational

\section{Introduction}

Improvement in the acute care and long-term medical management of spinal cord injured people has meant that these individuals' life expectancy has begun to approach that of the general population. ${ }^{\top}$ One consequence of this fact is that rehabilitation research and service provision has increasingly emphasised the importance of gaining a better understanding of the quality of life and post-injury achievements of persons with spinal cord injury (SCI). ${ }^{2}$ Because of the relative youthfulness of the spinal cord injured population, with most injuries occurring when people are younger than 30 years of age, ${ }^{3}$ the social and vocational rehabilitation of these individuals is of particular importance, not just to the patients themselves but also to the administrators of various health and social security organisations. While there are a variety of rehabilitation objectives for this patient group (including independence in activities of daily living, economic independence, and productive involvememt in community organisations) the gaining of, or return to, paid employment has long been regarded as one of the most important long-term rehabilitation goals. ${ }^{4}$ There are many arguments for the primacy, or at least the centrality, of vocational as opposed to avocational goals in rehabilitation, but one reason researchers such as Garvin ${ }^{5}$ have argued for the priority of work in the rehabilitation process is that (for the majority of people) being unemployed is associated with lowered

Correspondence: GC Murphy psychological well being. ${ }^{6,7}$ Applying this general finding to people with spinal cord injuries, (only a minority of whom work following their injury) 8,9 implies that there is significant opportunity for improving the psychological well-being of spinal cord injured persons by increasing their vocational achievements post injury.

Results in support of the proposed positive relationship between job seeking and self-perceived quality of life were reported by Cushman and Hassett ${ }^{10}$ in their recent study of adaptation following spinal cord injury. They found that those who sought employment reported having a significantly higher $(P<0.01)$ quality of life than those who did not attempt to work post injury. Although those currently employed at the time of the study (ie 10 or 15 years post injury) reported a superior quality of life compared with those unemployed, the difference did not reach statistical significance. These differing findings reported by Cushman and Hassett suggest that the relationship between well-being and employment in this population is complex, and emphasises the importance, in any study of post-injury achievement, of using more than one measure of key criterion variables (such as employment) if we are to better understand the rehabilitation process following spinal cord injury.

This study is part of a program of research centring on post-accident employment outcomes. With respect to the population of the Spinal Cord Injured, the issues for investigation have been identified as: (a) establishing the nature and extent of employment following spinal cord injury; (b) identifying predictors 
of employment following spinal cord injury; and (c) identifying factors which may be modified to enhance the vocational development of people with spinal cord injury (ie the ongoing process of career choice, training or return to work, and continued employment). The main aims of this study were: (a) to identify the employment status of a sample of Australian spinal cord injured persons and to compare this with their pre-injury employment status; and (b) to examine the extent to which the employment-related achievements of these individuals, post-injury, could be predicted from a combination of demographic and injury variables.

\section{Methods}

The present study was designed to overcome some of the limitations related to the measurement of employment found in many previous studies of vocational achievement following spinal cord injury. These have been described in detail by Murphy and Athanasou, ${ }^{8}$ who made several recommendations to guide future research in this field. In line with their recommendations to minimise ambiguity associated with the interpretation of obtained employment rates, the present study was designed with the key feature of using standardised definitions of employment status. To this end, the survey questions covering details of post-injury work were constructed to yield labour statistics comparable with the standard definition of labour force used by the International Labour Office, which defines those in the labour force as those 'employed' or 'actively looking for work'. Thus the survey data enabled the calculation of the 'labour force participation rate' (ie the proportion of the population in the labour force) as well as the actual unemployment rate (ie the proportion of the labour force who were actively seeking employment). Those defined as not being in the labour force are those 'not working' and 'not looking for work'. The second noteworthy design feature of the present study is that it used as a criterion variable a measure of employment durability. This measure ('workrate') was included in recognition of the fact that, regardless of an individual's employment status at any point in time, many individuals who gain employment post-injury, subsequently discontinue working. ${ }^{11}$

Survey subjects were all patients of the Austin Hospital Spinal Injuries Unit. This Unit, located in metropolitan Melbourne, is the sole specialist treatment and rehabilitation facility in the state of Victoria for those suffering spinal cord injury, and as such, services the entire population of Victorian-based spinal cord injured, whether living in metropolitan Melbourne, provincial cities or rural areas. The Unit has a policy of life-long regular review of its discharged patients. Patients attending for review by the Austin Hospital Spinal Injuries Unit were asked to complete a survey which was distributed by the rehabilitation nurses. The survey was designed to be easily completed by people with limited fine-motor skill, in that most of the questions required respondents simply to check a box. The survey took $10-15 \mathrm{~min}$ to complete, depending on the amount of assistance required. The 22 survey questions were designed to measure demographic and injury variables (age, sex, impairement type, length of initial admission, years since injury, compensation status), educational attainments both pre- and post-injury, and employment and occupational status both pre- and post-injury, including months worked post-discharge. In addition, the survey canvassed details of any post-injury attempts to gain employment and, where applicable, respondents' perceptions of the reasons for their not working. The survey was carried out in 1993. Of 300 patients approached, $219 \quad(71 \%)$ completed the survey. Eighty-one subjects either declined to participate or were considered by staff to be inappropriate for the study because of their physical rehabilitation program's being incomplete (ie scheduled for further readmissions). No demographic information was collected regarding the characteristics of the 81 nonparticipants.

The age, years since injury and the length of initial hospitalisation of the 219 responding subjects are shown in Table 1. The subjects were predominantly male $(83 \%)$ and most had not completed secondary high school $(76 \%)$ at the time of their injury. Sixty-six percent of the subjects were working full-time at the time of injury, and just over half $(52 \%)$ had entitlements to some 'third-party' (insurance) compensation as a result of their injury. The number of subjects in each of the major impairment categories were: complete tetraplegia, 44; incomplete tetraplegia, 54; complete paraplegia, 72; incomplete paraplegia, 49.

The survey yielded information on nine predictor and two criterion variables. The predictor variables (which included all but one of the comparable demographic and injury factors identified as significant by DeVivo, Rutt, Stover and Fine ${ }^{11}$ ) were as follows: age; sex (female, male); occupational classification on admission (white collar, blue collar, unemployed); compensation entitlement on admission (no, yes); impairment type (tetraplegia, paraplegia); employment status prior to injury (working full-time, other); level of secondary schooling completed prior to

Table 1 Age, years since injury, length of admission and workrate of study participants $(n=219)$

\begin{tabular}{lrrrr}
\hline Variable & Mean & \multicolumn{1}{c}{$S D$} & Median Range \\
\hline $\begin{array}{l}\text { Age at time of survey } \\
\quad \text { years) }\end{array}$ & 42.56 & 14.47 & 39.0 & $16-86$ \\
$\begin{array}{l}\text { Years since injury } \\
\begin{array}{l}\text { Length of initial admission } \\
\text { (months) }\end{array}\end{array}$ & 12.45 & 10.52 & 10.0 & $1-43$ \\
Workrate* & 8.09 & 4.68 & 7.0 & $1-35$ \\
\hline
\end{tabular}

$*_{n}=161$ 
injury (year 9 or below, through to year 12); other preinjury qualification (no other, through to degree); and, additional qualifications post-injury (none, some). (Please note that the sub-categories assigned lower numerical values have been listed first within the brackets). The two criterion variables were: current labour force status; and, workrate. Labour force status is a dichotomous variable ('in the labour force' $v s$ 'not in the labour force') and workrate is a continuous variable which is derived from the number of months in employment post-injury divided by the number of months available for employment post-injury. Time participants spent in study, retirement or undertaking formal rehabilitation programs was not classified as time 'available' for employment. Scores on this variable thus range from zero to 100 . As has been previously explained, workrate was included as a criterion variable as it was believed some measure of the substantiality of post-discharge employment was an important index of successful vocational rehabilitation, over and beyond the respondents' labour force status at the time of the survey.

\section{Results}

The data were analyzed first to provide a description of the respondents' situations prior to, and subsequent to, their injury and second to identify any significant predictors of post-injury employment and related achievements.

The educational and vocational achievements of respondents were examined by comparing their status pre and post-injury. These results are presented in Tables 2 and 3 . The data in Table 2 indicates that, preinjury, the majority of respondents had not completed secondary schooling, and had no additional postschool qualifications. Post-injury, the educational

Table 2 Educational achievements of study subjects pre and post injury $(n=219)$

\begin{tabular}{lc}
\hline Education & Valid Percent \\
\hline Pre-injury secondary schooling* & \\
Completed year 9 or below & 36 \\
Completed year 10 & 23 \\
Completed year 11 & 17 \\
Completed secondary school & 24 \\
Pre-injury post-school qualifications* & \\
No other & 60 \\
Trade & 20 \\
Certificate, Diploma or Degree & 20 \\
Post-injury education & \\
No additional studies & 67 \\
High school & 5 \\
Technical and further education & 16 \\
University & 8 \\
Other qualifications & 4 \\
\hline
\end{tabular}

$*_{n}=217$ achievements of the majority had not changed, since more than two-thirds of the subjects had undertaken no additional study subsequent to their injury. Encouragingly, about a quarter of respondents (24\%) reported having undertaken study for technical college or university awards.

The data in Table 3 indicate that besides the expected large drop in full-time employment, the major change in labour force status, post-injury, is the large increase, not in unemployment per se, but in those dropping out of the labour force (ie those not available for, or looking for, work). The largest percentage of respondents $(59 \%)$ are in this category.

The reasons given by respondents for dropping out of the labour force are presented in Table 4 which indicates that, besides the obvious reasons associated with respondents' health or age, a significant minority of those without employment are not working or looking for work because they judge it too difficult an outcome to achieve (ie a perceived lack of suitable jobs or a perception of 'practical difficulties' which are a barrier to their employment).

Discriminant function analysis was then conducted to determine if, by using demographic and injury data, separation of the groups 'in the labour force' vs 'not in the labour force' could be achieved. After excluding 30 cases which had at least one missing value for a discriminating variable, 189 cases were available for this analysis. Discrimination between the groups could be reliably achieved by using the nine predictors $\left(\chi^{2}(9)=37.10, \quad P<0.001\right)$. The classification result from the discriminant function analysis indicates that overall $70 \%$ of the cases were correctly classified, with

Table 3 Labour force status of study subjects pre and post injury

\begin{tabular}{lcc}
\hline Employment status & $\begin{array}{c}\text { Pre-injury status } \\
(n=216)\end{array}$ & $\begin{array}{c}\text { Post-injury status } \\
(n=219)\end{array}$ \\
\hline Employed full-time & $66 \%$ & $26 \%$ \\
Employed part-time & $7 \%$ & $11 \%$ \\
Unemployed & $5 \%$ & $4 \%$ \\
Not in the labour force & $22 \%$ & $59 \%$ \\
\hline
\end{tabular}

Table 4 Major reasons for not having, or seeking, a job $(n=135)$

\begin{tabular}{lc}
\hline Reason & Valid Percentage \\
\hline Health problems & 29.5 \\
Lack of suitable jobs & 27.1 \\
Practical difficulties & 16.8 \\
Retired & 16.3 \\
Financial considerations & 13.9 \\
Study or training & 11.8 \\
Domestic responsibilities & 11.1 \\
Negative attitude of employers & 5.1 \\
Undertaking a rehabilitation program & 2.9 \\
\hline
\end{tabular}


$78.1 \%$ of those not in the labour force being correctly classified and $60.7 \%$ of those in the labour force being correctly predicted.

The pooled within-group correlations between the predictors and the discriminating function (see Table 5) suggest that the best predictors for distinguishing between those who are in the labour force post-injury and those who are not are: (a) impairment type (0.624); (b) study since injury (0.455); occupational classification on admission $(-0.412)$; and, prior schooling (0.408). In line with the recommendations of Tabachnick and Fidell, ${ }^{12}$ loadings less than 0.30 are not interpreted. Thus the results of this analysis indicate the following patterns of labour force participation: (1) those whose impairment was paraplegia as opposed to tetraplegia were more likely to be in the labour force; (b) those who had done some study since injury were more likely to be in the labour force; (c) those who had higher occupational classifications at the time of admission for their injury were more likely to be in the labour force; and (d) those who had higher levels of schooling prior to injury were more likely to be in the labour force.

Finally, a standard multiple regression was performed with the aim of predicting the amount of time the individual had worked post injury. As mentioned previously, the criterion variable 'workrate' was

Table 5 Pooled within-groups correlations between discriminating variables and the discriminant function $(n=189)$

\begin{tabular}{lc}
\hline Predictor variables & Correlation with function \\
\hline Impairment type & 0.624 \\
Post-injury education & 0.455 \\
Occupation pre-injury & -0.412 \\
Length of schooling pre-injury & 0.408 \\
Other qualifications pre-injury & 0.168 \\
Sex & 0.114 \\
Employment status pre-injury & 0.110 \\
Compensation entitlement & -0.078 \\
Age & -0.041 \\
\hline
\end{tabular}

calculated by dividing the months worked post discharge by the number of months available for work. Individuals with no time available for work (ie those in continuous study, retirement or formal rehabilitation) were excluded from this analysis. The sample of interest decreased to 161 subjects and missing data further reduced the sample size to 137. The predictor variables used in the discriminant function analysis were also employed in this analysis. The results of this multiple regression are presented in Table 6.

The information in Table 6 indicates that the multiple correlation coefficient between these nine predictor variables and the criterion (workrate) was 0.648 , which was significant at $P<0.001$, and accounted for $42 \% \quad(37.9 \%$ adjusted $)$ of criterion variance. Six predictors contributed significantly to the equation, and the beta weights in the table indicate that the order in which these variables contribute to the successful prediction of workrate is as follows: impairment type, sex, age, study since injury, level of prior schooling, and compensation entitlement. Thus the pattern of predictors of post-injury workrate which emerged was as follows: those with a diagnosis of paraplegia tended to have spent more months in work; males spent more time in work than did females; the older respondents had worked more post-injury than had the younger respondents; those who had undertaken some post-injury study were more likely to have had work post-injury; those with higher levels preinjury of secondary education were more likely to have increased months of post-injury work; and, those with some compensation entitlement were less likely to have post-injury work than were those without such entitlements.

The squared semi-partial correlations $\left(\mathrm{sr}^{2}\right)$ listed in Table 6 indicate the proportion of criterion variance uniquely explained by each individual, significant predictor. Impairment type explains the greatest amount $(12 \%)$ of the variance in post-injury workrate, while compensation entitlement explains the least $(2 \%)$ among the significant predictors.

Table 6 Standard multiple regression of predictor variables on workrate $(n=137)$

\begin{tabular}{lrccc}
\hline Variable & \multicolumn{1}{c}{ B } & $\beta$ & $T$-value & \multicolumn{1}{c}{$s r^{2}$} \\
\hline Age & 0.824 & 0.259 & $3.501^{* * *}$ & 0.057 \\
Sex & 33.059 & 0.303 & $4.299^{* * *}$ & 0.084 \\
Impairment type & 28.334 & 0.352 & $5.122^{* * *}$ & 0.120 \\
Employment status pre-injury & 5.881 & 0.062 & 0.868 & 0.032 \\
Length of schooling pre-injury & 7.211 & 0.208 & $2.646^{* *}$ & \\
Occupation pre-injury & -7.394 & -0.109 & -1.372 & 0.849 \\
Other qualifications pre-injury & 2.562 & 0.066 & $3.493^{* * *}$ & 0.056 \\
Post-injury education & 21.235 & 0.254 & $-2.076^{*}$ & 0.020 \\
Compensation entitlement & -11.726 & -0.146 & Adjusted $r^{2}$ & 0.420 \\
(Constant) & -74.176 & & Multiple $r$ & 0.379 \\
& & &
\end{tabular}

$* P<0.05 ; * * P<0.01 ; * * * P<0.001$ 


\section{Discussion}

The substantive results of the study can be discussed, separately, with respect to education and employment achievements. Educationally, a major finding of the present study was that, in spite of an initial low level of secondary school education, two thirds of these respondents reported undertaking no further education following their spinal cord injury. In view of the traditional correlation between education and increased rates of employment, ${ }^{13}$ this absence of post-injury education represents a significant handicap with respect to employment, and presents a challenge to those offering vocational guidance or related services to people with a spinal cord injury.

Regarding employment and related achievements, a number of important findings emerged. First, with respect to the actual percentages of respondents who were employed, the current finding that $37 \%$ of the respondents were in either full-time or part-time work, suggests that, as a group, the vocational achievements of this sample of Australian spinal cord injured persons are quite comparable to those of similar groups in North America and Great Britain. Thus Young, et al. ${ }^{14}$ found that $27 \%$ of their stratified random sample of persons with SCI living in Texas were employed, and Castle ${ }^{15}$ ascertained that $31 \%$ of ex-patients of the Duke of Cornwall Spinal Treatment Centre in Salisbury were in paid employment at the time of follow-up, one to seven years post injury. It is important to note that while there is some general consistency across these studies in terms of the percentages of respondents employed at the time of survey, such employment rates can only be meaningfully compared if the samples involved in the particular studies are equivalent in terms of such key subject characteristics as age of respondent, time since injury, level of injury, and educational or occupational background. Unfortunately the methods used in the three studies does not allow a direct comparison of participants' characteristics on all key variables. It appears that the current study's sample is most similar to that of Young and colleagues, ${ }^{14}$ in that the age at the time of survey, age at time of injury, years since injury, and previous educational qualifications are similar in both studies, although, curiously, the percentage of respondents with incomplete lesions was markedly different, with the Texan sample containing $16 \%$ incomplete impairments and the Australian sample a much larger proportion, at $47 \%$.

Besides equivalence of subjects, another factor to consider when comparing employment rates from the different studies is the comparability or otherwise of government support for post-injury employment. The extent to which government legislation actually encourages or discourages the seeking of employment obviously impacts on average levels of post-injury employment or unemployment in particular jurisdictions. Thus the higher rates of post-injury employment (approximately $70 \%$ ) reported by Siosteen, et al. ${ }^{16}$ in their study of Swedish people who had sustained a spinal cord injury, was undoubtedly facilitated by the vast community provisions routinely provided in Sweden to assist even those with severe spinal cord injuries to earn an income. Notwithstanding the difficulties in establishing actual equivalence between studies, the present results when combined with those of previous related studies, do illustrate the significant vocational potential of people with spinal cord injury and hopefully can provide realistic encouragement for those individuals wishing to gain employment or return to work following their injury.

A major finding with respect to the impact of spinal cord injury on the employment status of the study participants was that the greatest change involved dropping out of the labour force. Thus while there was a large drop in full-time employment following injury (from $66 \%$ pre-injury to $26 \%$ post-injury), those people who moved from being full-time employed were not, at the time of this post-injury survey, unemployed per se but rather were not available for work nor actively seeking employment. That is, in spite of what may intuitively have been expected, there was not a large increase in unemployment per se (in fact this remained rather stable) but rather the majority of these former full-time employees had ceased participating in the labour force. This finding supports the usefulness of the current study's approach in using the standard employment measures of the International Labour Office wherein 'unemployment' is a separate category from 'not in the labour force'. Failure to separate these two groups, as has been done in many similar studies, can produce ambiguous results. Thus McShane and $\operatorname{Karp}^{17}$ used only a dichotomous measure of employment and reported that $58 \%$ were not in paid employment. What is unknown from such a result is the proportion of those classified as 'unemployed' who were actively seeking work as opposed to those who, for whatever reason, were unavailable for work. From the practical point of view it may in fact be more important initially to identify those who, by dropping out of the labour force, severely limit their changes of gaining paid employment.

In view of the large number of respondents identified as not being in the labour force, the results of the discriminant function analysis are of special importance in our attempt to understand the process of vocational development post injury. The current analysis identified four main predictors of labour force participation (impairment, study since injury, previous occupational title and previous level of secondary schooling). Of these, only one variable (study since injury) is amenable to influence by therapists or counsellors providing services to this group of injured people. In view of the previously discussed finding concerning the relatively low rate of post injury study (around 24\%) it may well be that one of the most practical ways for professionals to assist in raising the vocational achievements of persons with spinal cord 
injury is via educational guidance. In suggesting the importance of undertaking formal study as part of a patient's rehabilitation program, it is recognised that the results of the current correlational study do not preclude the important influence of other variables (eg need for achievement) which may be commonly correlated with both educational and vocational achievements.

One interesting result from the discriminant function analysis was that associated with the classification results. While overall more than $70 \%$ of cases were correctly classified, it was noteworthy that the discriminant function was more able to predict those not in the labour force $(78 \%)$ than those in the labour force $(60 \%)$. It appears that many spinal cord injured people who say they are in the labour force have characteristics similar to those not in the labour force. This suggests that additional factors (eg functional abilities, psychological state) may need to be measured if we are to more accurately predict those who are in the labour force.

The final employment-related result to be discussed is that associated with the multiple regression, which identified six variables to be predictors of the amount of employment following injury (impairment, sex, age, study since injury, previous level of secondary schooling, and compensation entitlement). In line with the results of the discriminant function analysis, study since injury was the only predictor open to influence by health professionals providing services to the spinal cord injured.

With respect to the multiple regression results, it is noteworthy that while a reasonably high multiple correlation result was obtained $(r=0.648)$, and the amount of explained variance $(37.9 \%)$ was large enough to have practical significance, the amount of unexplained variance in workrate suggests that we need to examine additional variables if we are to better understand the factors which correlate with the amount of work gained by a person following spinal cord injury. One obvious variable which should be considered in further research but which, for practical reasons, was not able to be included in the present study, is a measure of functional independence, to complement the impairment information used in this and similar studies. Additionally, psychological variables (such as those related to work motivation) may prove to explain practically significant amounts of employment variance.

The results from this survey of employment need to be interpreted with the limitations of the methodology recognised. In the current survey a convenience sampling approach was adopted in that only those attending for review at the Austin Hospital during the time of the survey were able to participate. Adopting such a method of subject recruitment obviously limits our ability to generalise the findings from the research. The final sample of participants however seems not to be atypical of the population of Australian spinal cord injured in that their age at injury, ratio of males to females, impairment type and compensation entitlement (ie percentage receiving workers' compensation or transport accident insurance) were all comparable to the characteristics of the subjects studied by Dowda $^{18}$ in his population survey of traumatic spinal cord injury cases admitted to the Royal North Shore Hospital (Sydney) during the first 25 years of operation of that hospital's Spinal Injuries Unit. It could be argued that if participants had had a longer period of time since injury more may have found employment. However, given that it has been reported that most of those who do gain jobs, do so within the first 10 years, ${ }^{19}$ the time since injury which did obtain in the present study (mean of 12.5 years) suggests that, as a group, the subjects had reasonable opportunity to gain employment.

At the present time the current study has reinforced the vocational potential of people with a spinal cord injury and has identified one variable (post-injury study) which seems to be significantly involved in two crucial stages of post-injury vocational development: the decision to seek employment and the actual amount of time spent in employment post-injury. Services in this area may need to be reviewed for their capacity to better support those spinal cord injured patients undergoing rehabilitation who decide that they wish to return to work or gain employment following stabilisation of their condition and their attainment of independence in key areas of living.

\section{References}

1 Tariccio $\mathrm{M}$ et al. The social and vocational outcome of spinal cord injured patients. Paraplegia 1992; 30: 214-219.

2 Stensman R. Adjustment to traumatic spinal cord injury. A longitudinal study of self-reported quality of life. Paraplegia 1994; 32: $416-422$.

3 Yarkony G. Spinal cord injury rehabilitation. In: Lee B, Ostrander L, Cochran G, Shaw W (eds). The spinal cord injured patient. WB Saunders: Philadelphia 1991, pp 265-282.

4 Connors K, Graham R, Pulso R. Playing store: Where is the vocational in vocational rehabilitation? Psychosocial Rehabil $J$ 1987; X(3): $21-33$.

5 Garvin W. Vocational guidance and counselling: The core of the rehabilitation process. J Appl Rehabil Coun 1981; 12: 205-207.

6 Jahoda M, Lazarsfield P, Zeisel H. Marienthal: The sociography of an unemployed community. Tavistock: London 1971.

7 Ezzy E. Unemployment and mental health. Soc Sci Med 1993; 37: $41-52$.

8 Murphy G, Athanasou J. Vocational potential and spinal cord injuries: A review and evaluation. J Appl Rehabil Coun 1994; 25: $47-52$.

9 Noreau L, Shephard R. Return to work after spinal cord injury: The potential contributions of physical fitness. Paraplegia 1992; 30: $563-572$

10 Cushman L, Hassett J. Spinal cord injury: Ten and fifteen years after. Paraplegia 1992; 30: 690-696.

11 DeVivo M, Rutt RD, Stover SL, Fine PR. Employment after spinal cord injury. Arch Phys Med Rehabil 1987; 68: 494-498.

12 Tabachnick B, Fidell L. Using multivariate statistics. Harper Collins: New York 1989

13 Becker G. Human capital. National Bureau of Economic Research: New York 1975.

14 Young M et al. Vocational status of persons with spinal cord injury living in the community. Rehabil Coun Bull 1994; 37: 229 243. 
15 Castle R. An investigation into the employment and occupation of patients with a spinal cord injury. Paraplegia 1994; 32: 182 187.

16 Siosteen B et al. The quality of life of three functional spinal cord injury subgroups in a Swedish community. Paraplegia 1990; 28: $476-488$

17 McShane S, Karp J. Employment following spinal cord injury. Rehabil Psychol 1993; 38: 27 - 40.

8 Dowda D. Spinal cord injury: physical and social outcomes. (Master of Public Health thesis). University of Sydney: Sydney, 1982.

19 Krause J. Employment after spinal cord injury. Arch Phys Med Rehabil 1992; 73: $163-169$. 